\title{
COMPARATIVE EVALUATION OF THE EFFECT OF INTRALIGAMENTARY INJECTION OF DEXAMETHASONE AND PIROXICAM ON POSTOPERATIVE PAIN IN TEETH WITH SYMPTOMATIC IRREVERSIBLE PULPITIS: A RANDOMIZED CONTROLLED TRIAL
}

\author{
Safwa E. Abd El-Glil *, Siza Y. Zakhary**, Maged M. Negm* and Fatma M. Abu-Naaem ***
}

\begin{abstract}
Postoperative pain management is a challenging problem in the clinical practice of endodontics. It has been postulated that intraligamentary injection enables the application of anti-inflammatory agents directly in the periapical region.

Aim: Assess and compare the efficacy of local intraligamentary injection of dexamethasone and piroxicam on postoperative pain in mandibular molars with symptomatic irreversible pulpitis.

Subjects and Methods: Forty-two patients were included and randomly assigned to three equal groups $(\mathrm{n}=14)$. After administration of standard inferior alveolar nerve block, each participant received intraligamentary injection of $0.4 \mathrm{ml}$ of either $8 \mathrm{mg} / 2 \mathrm{ml}$ dexamethasone, $20 \mathrm{mg} / \mathrm{ml}$ piroxicam or $2 \%$ mepivacaine. Standard endodontic treatment was performed in a single visit. The pain was assessed by means of the Numerical Rating Scale preoperatively and postoperatively after 4, 6, 12, 24 and 48 hours. All demographic, baseline and outcome data were collected and statistically analyzed.
\end{abstract}

Results: There was no significant difference between the three groups regarding age, gender and preoperative pain. There was a significant reduction in pain in all groups, however, there was a statistically significant reduction in postoperative pain in piroxicam group compared to the mepivacaine group at all time intervals. There was a statistically significant reduction in postoperative pain in the dexamethasone group when compared to the mepivacaine group only at 4 , 24 and 48 hours. However, there was no significant difference found at 6 and 12 hours. There was no significant difference between dexamethasone and piroxicam groups.

Conclusions: It was concluded that preoperative intraligamentary injection of dexamethasone and piroxicam show a significant success in reducing postoperative pain compared to mepivacaine with no preference regarding using either of them.

KEYWORDS: Dexamethasone, Piroxicam, Symptomatic irreversible pulpitis, intraligamentary injection, postoperative pain.

\footnotetext{
* MSc Degree Student, Endodontic Department, Faculty of Dentistry, Cairo University

** Professor, Endodntic Department, Faculty of Dentistry, Cairo University

*** Lecturer, Endodontic Department, Faculty of Dentistry, Cairo University
} 


\section{INTRODUCTION}

Endodontic postoperative pain management is one of the challenging problems in the clinical practice of endodontics ${ }^{(1,2)}$. Although this pain usually decreases after root canal treatment, there may be residual symptoms left due to inflammation ${ }^{(3,4)}$. It has been reported that up to $80 \%$ of patients with preoperative pain, will report pain after treatment, which might range from mild to severe ${ }^{(5,6)}$.

Many mechanisms have been proposed to explain the reason for postoperative pain including the sensitization of nociceptors by inflammatory mediators (e.g. prostaglandins, leukotrienes, bradykinin, platelet-activating factor and substance P) ${ }^{(4,7)}$. Endodontic treatment can lead to the release of inflammatory mediators into the surrounding periapical tissues, causing pain fibers to be directly stimulated or sensitized ${ }^{(8)}$.

Most postoperative pain is usually well managed with non-steroidal anti-inflammatory agents (NSAIDs) and glucocorticoids. They primarly act through the inhibition of cyclooxygenase enzymes thus preventing inflammation and sensitization of the peripheral nociceptors ${ }^{(9)}$.

Intraligamentary injection of local anaesthesia was reported to be an effective and easy way to control severe pain during endodontic treatment mainly in mandibular teeth ${ }^{(10)}$. It has been postulated that the intraligamentary injection enables the local application of anti-inflammatory agents directly in the periapical region ${ }^{(11,12)}$.

To our knowledge, there was a lack of studies investigating the effect of intraligamentary injection of dexamethasone and piroxicam on the control of post-endodontic pain. Thus this study is conducted to assess the effect of intraligamentary injection of dexamethasone $(0.4 \mathrm{ml}$ of $8 \mathrm{mg} / 2 \mathrm{ml})$ vs. piroxicam $(0.4 \mathrm{ml}$ of $20 \mathrm{mg} / \mathrm{ml})$ compared with a local anaesthetic solution ( $0.4 \mathrm{ml}$ of mepivacaine
$\mathrm{HCl} 36 \mathrm{mg} / 1.8 \mathrm{ml}+$ levonordefrin $\mathrm{HCl} 0.108 \mathrm{mg} /$ $1.8 \mathrm{ml}$ ) on postoperative pain in teeth with symptomatic irreversible pulpitis.

\section{SUBJECTS AND METHODS}

\section{Study design and sample size}

The design of this study was a parallel, doubleblinded, randomized clinical trial that was approved by the institutional review boards/ethical committees (IRBs/ECs) of the Faculty of Dentistry, Cairo University. It was registered on www.clinicaltrials. gov (Code: NCT03745105).

The sample size was calculated using G*Power 3.1.9.2 (Die Heinrich-Heine-Universität Düsseldorf-Germany), based on an alpha error $=0.05$ and a power of 0.8 . A total sample of 33 was calculated, 11 in each group, would be required to detect differences between the study groups. This number was increased to a total number of 42, 14 in each group to correct for anticipated missing data.

\section{Inclusion and exclusion criteria}

The patients were recruited from the outpatient clinic of the Department of Endodontics. The inclusion criteria for patients selection were as follow: age (20-60 years), healthy patients (ASA I, II). Diagnosed with SIP in mandibular posterior teeth with a history of sharp moderate to severe pain and no widening in the periodontal ligament (PDL).

Patients exclusion criteria included those who are allergic to anaesthetics or drugs used in the study, pregnant or nursing females, those having hemostatic disorders or using anticoagulant therapy during the last month and those consuming analgesics or corticosteroids during the last 12 hours before treatment.

\section{Randomization and allocation}

After the explanation of the treatment procedure, all the included patients signed a printed informed 
consent that explains the involved procedures and the possible risks. They were randomly divided into three equal groups of 14 patients, where the random sequence was generated by the Center of EvidenceBased Dentistry, Faculty of Dentistry, Cairo University using computer software, (http://www. random.org/) and a letter A was given for intervention no.1(dexamethasone), letter B for intervention no.2 (piroxicam) and $\mathrm{C}$ for comparator(mepivacaine). For allocation concealment, eight-folded numbered papers were packed in opaque sealed envelopes to be dragged by the patients at the treatment visit.

\section{Procedural steps}

Patients included were asked to mark his/her level of pre-operative pain on NRS pain diary form. Each patient received a standard mandibular IANB injection of $1.8 \mathrm{ml}$ of $2 \%$ mepivacaine with 1: 20,000 levonordefrin (Mepecaine -L, Alexandria Co.-Egypt). Dexamethasone or piroxicam cartridges were prepared by removing the rubber plungers from the standard anaesthetic cartridges, washed out from its contents and autoclaved. This method of preparation was identical to the method as set out in El-sharrawy's article on supplemental intraligamentary injection of fentanyl and mepivacaine ${ }^{(13)}$ Empty cartridges were filled with $0.4 \mathrm{ml}$ of $8 \mathrm{mg} / 2 \mathrm{ml}$ dexamethasone (AMRIYA pharmaceutical, Egypt) or $0.4 \mathrm{ml}$ of $20 \mathrm{mg} / \mathrm{ml}$ piroxicam (Feldene, Pfizer, Egypt) from the vial to the cartridge using insulin syringe by the assistant at the time of the operation for the operator to be blind.

After 15 minutes of IANB injection, intraligamentary injection of $0.4 \mathrm{ml}$ of either dexamethasone $(8 \mathrm{mg} / 2 \mathrm{ml})$, piroxicam $(20 \mathrm{mg} / \mathrm{ml})$ or $2 \%$ mepivacaine $+1: 20,000$ levonordefrin was administered. They were injected using a 27 -gauge short disposable needle set on an intraligamental pressure syringe (PAROJECT ${ }^{\circledR}, \quad$ RØNVIG, Daugaard, Denmark). The needle was placed in the gingival sulcus at a 30 - degree angle to the long axis of the tooth where $0.2 \mathrm{ml}$ was deposited on each mesial and distal aspect of the tooth. Single-visit endodontic treatment was done using M-Pro rotary system (IMD, Shanghai, China) and irrigation was done using $2.5 \%$ sodium hypochlorite followed by $5 \mathrm{ml}$ of $17 \%$ EDTA (Prevest,DenPro Limited, India) solution and final saline rinse. Obturation was carried out using modified single-cone technique with a resin sealer (ADSEAL, Meta Biomed Co. Ltd, Korea) then the access cavity was sealed with a temporary filling material (MD Temp, Meta Biomed CO., LTD, Korea). After treatment, each patient received a pain diary form to record the intensity of pain felt after 4, 6, 12, 24 and 48 hours.

\section{Study outcome}

The outcome of the study was postoperative pain intensity which was measured using an 11-point Numerical Rating Scale (NRS) where the endpoints are the extremes of no pain and worst pain. Pain intensity was assigned into one of four pain categories: none (0); mild (1-3); moderate (4-6); and severe $(7-10)$.

\section{Data collection and statistical analysis}

Data were collected and analyzed where continuous data were presented as mean and standard deviation and tested for normality using the Shapiro Wilk test. ANOVA test was used for analyzing normally distributed data, while the Kruskal Wallis test was used for analyzing non-normally distributed data followed by the Mann-Whitney $\mathrm{U}$ test for pairwise comparison. While categorical data were presented as frequencies and percentages. Chi-square test was used for analyzing categorical tests where Pearson's Chi-square test was used when the expected values of the categories were not less than 5 while the likelihood ratio was used when the expected values were less than 5 . A p-value of less than 0.05 was considered statistically significant. 


\section{RESULTS}

A total of 42 participants were assessed for eligibility and included in the study and were randomly distributed between three groups $(n=14)$. The trial design followed the CONSORT 2010. The flow of the participants throughout the study is presented in (Figure 1).

There was no significant difference found between the two groups regarding age, gender and preoperative pain $(p>0.05)$. Baseline demographic data is presented in (Table 1).

Before treatment the highest and lowest pain levels were found in dexamethasone group $(7.29 \pm 1.38)$ and mepivacaine group $(6.86 \pm 1.23)$, respectively. However, the Kruskal-Wallis test indicated no significant differences $(\mathrm{P}=0.883)$.

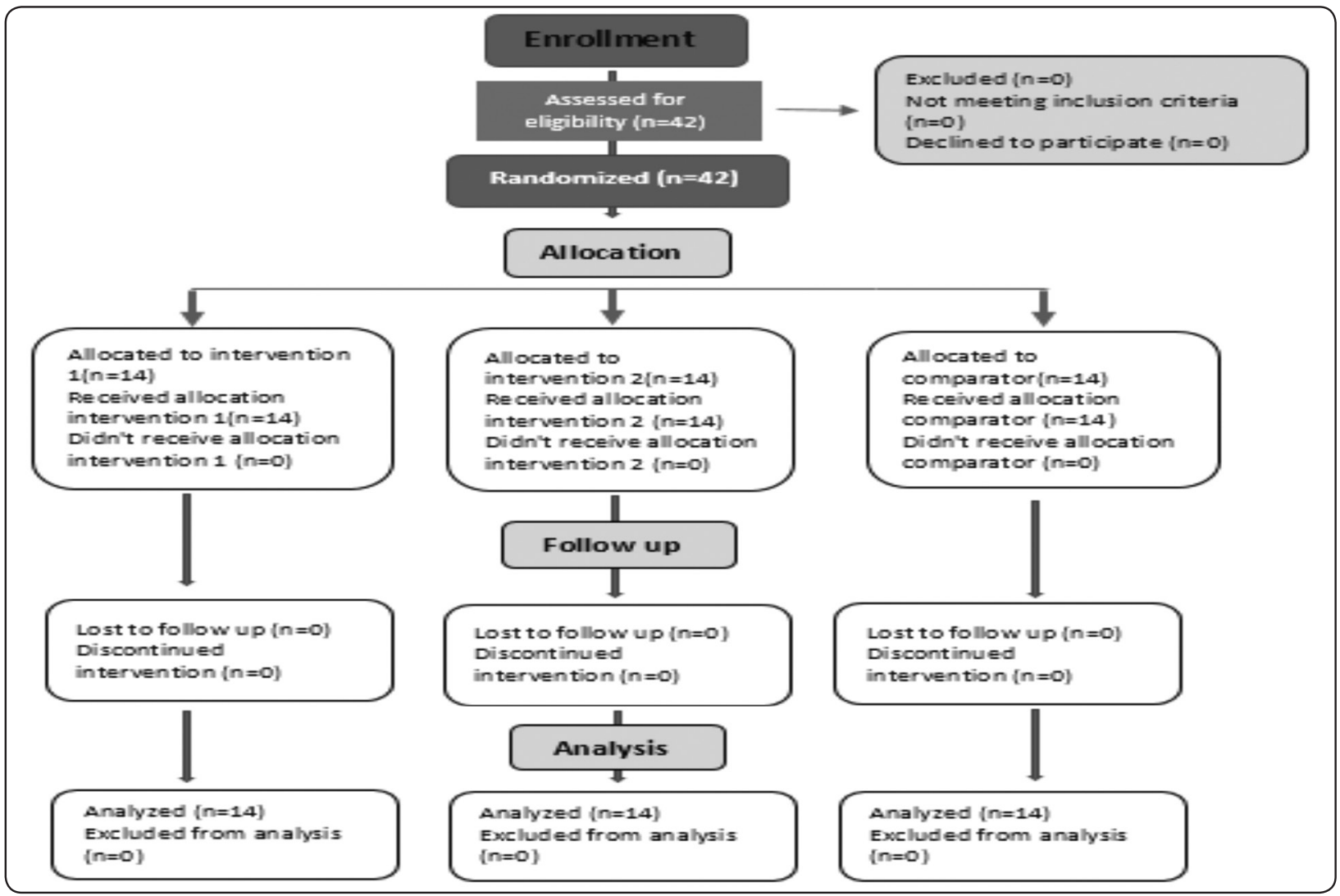

Fig. (1): Participants flowchart

TABLE (1) Baseline demographic features of participants in the study groups

\begin{tabular}{|c|c|c|c|c|}
\hline Variable & Dexamethasone & Piroxicam & Mepivacaine & P-value \\
\hline Age (y) Mean \pm SD & $34.43 \pm 9.26$ & $32.64 \pm 10.49$ & $35.14 \pm 6.95$ & 0.753 \\
\hline \multicolumn{5}{|l|}{ Gender } \\
\hline Male $[\mathrm{N}(\%)]$ & $4(28.6 \%)$ & $5(35.7 \%)$ & $7(50 \%)$ & \\
\hline Female $[\mathrm{N}(\%)]$ & $10(71.4 \%)$ & $9(64.3 \%)$ & $7(50 \%)$ & 0.493 \\
\hline \multicolumn{5}{|l|}{ Preoperative pain (NRS) } \\
\hline Mean \pm SD & $7.29 \pm 1.38$ & $7.07 \pm 1.07$ & $6.86 \pm 1.23$ & 0.883 \\
\hline
\end{tabular}


Postoperatively at all time intervals, the highest and lowest levels of pain intensity were found in mepivacaine group and piroxicam group, respectively. There was a statistically significant difference in pain intensity between the three groups $(\mathrm{P}<0.05)$. (Table 2)

Pairwise comparison using Mann-Whitney U test showed non-significant difference of postoperative pain reduction between dexamethasone and piroxicam groups, at all postoperative time intervals $(\mathrm{P}>0.05)$. While between the piroxicam group and mepivacaine group, the reduction was found to be significant at all postoperative time intervals $(\mathrm{P}<0.05)$. However, in the pairwise comparison between dexamethasone group and mepivacaine group, the reduction was found to be significant only at 4,24- and 48-hour intervals, and it was found to be non-significant between the two groups at 6- and 12-hour intervals. (Table 3)

TABLE (2) Mean and standard deviation (SD) values of postoperative pain intensity at different time intervals, and calculated p-value in the three groups

\begin{tabular}{|c|c|c|c|c|}
\hline $\begin{array}{l}\text { Group } \\
\text { Interval }\end{array}$ & Dexamethasone & Piroxicam & Mepivacaine & P-value \\
\hline 4 hrs (Mean \pm SD) & $3.36 \pm 2.1$ & $3.21 \pm 1.53$ & $5.14 \pm 1.99$ & $0.028 *$ \\
\hline 6 hrs $($ Mean \pm SD $)$ & $2.93 \pm 2.09$ & $1.93 \pm 1.33$ & $4.36 \pm 2.1$ & $0.012 *$ \\
\hline 12 hrs $($ Mean \pm SD $)$ & $2.5 \pm 2.38$ & $1.07 \pm 0.83$ & $3.64 \pm 1.69$ & $0.005^{*}$ \\
\hline 24 hrs $($ Mean \pm SD $)$ & $0.93 \pm 1.07$ & $0.43 \pm 1.34$ & $2.36 \pm 1.55$ & $0.001 *$ \\
\hline 48 hrs $($ Mean \pm SD $)$ & $0.29 \pm 0.47$ & $0.07 \pm 0.27$ & $1.36 \pm 0.84$ & $<0.001^{*}$ \\
\hline
\end{tabular}

*Significant at $p<0.05$

TABLE (3) Pairwise comparison of pain intensity between the three groups at different time intervals

\begin{tabular}{|l|c|c|c|c|c|}
\hline Group & At 4-hr & At 6-hr & At 12-hr & At 24-hr & At 48-hr \\
\hline Dexamethasone- piroxicam & 0.869 & 0.221 & 0.213 & 0.059 & 0.146 \\
\hline Piroxicam - mepivacaine & $0.013^{*}$ & $0.003^{*}$ & $<0.001 *$ & $0.001 *$ & $<0.001^{*}$ \\
\hline Dexamethasone - mepivacaine & $0.036^{*}$ & 0.075 & 0.168 & $0.012^{*}$ & $0.001^{*}$ \\
\hline
\end{tabular}

*Significant at $p<0.05$ 


\section{DISCUSSION}

The post endodontic flare-up has polyetiological predisposing factors; mechanical, chemical and microbial factors ${ }^{(14)}$. According to the systematic review by Sathorn et al.(2008) ${ }^{(15)}$, the prevalence of pain after root canal treatment has been reported between $3 \%$ and $58 \%$ of the patients.

Various classes of drugs have been studied for the management of post-treatment endodontic pain including NSAID's, acetaminophen, opioids and steroids ${ }^{(16)}$. Non-steroidal anti-inflammatory drugs (NSAIDs) have been used to control severe pain after endodontic treatment. Piroxicam was used in this study as it is a non-selective reversible antiinflammatory drug that inhibits cyclooxygenase enzymes (COX). It also inhibits the synthesis of thromboxane in platelets, thus preventing the secondary phase of platelet aggregation. It has a half-life of 50 hours in the plasma that has an advantage of decreasing the dose and improving compliance, particularly in elderly patients ${ }^{(17)}$.

Corticosteroids have also been used as an option to decrease postoperative pain owing to its anti-inflammatory effect. Glucocorticoids affect the immune response by inhibition of cytokine production (interferon $\gamma$; interleukin 1, 2, 3, and 6; and TNF- $\alpha$ ). They also induce the production of multiple proteins, such as lipocortin, which prevents arachidonic acid synthesis and its products 'such as prostaglandin'. They also produce vasocortin, which is involved in the suppression of edema ${ }^{(18)}$. Dexamethasone was used in this study because it has a strong anti-inflammatory effect 25 times more than that of endogenic cortisol ${ }^{(18)}$. It reduces the acute inflammatory response by suppressing vasodilation, migration of polymorphonuclear leukocytes and phagocytosis. Also, it inhibits the production of phospholipase-A2 and consequently reduces prostaglandin and leukotriene synthesis, decreasing polymorphonuclear leukocyte chemotaxis ${ }^{(19)}$.

It was reported that the intraligamentary injection of piroxicam and dexamethasone can significantly reduce postoperative pain in patients with symptomatic irreversible pulpitis ${ }^{(20,21)}$. Considering the local use of anti-inflammatory agents adjacent to the inflamed tooth to decrease inflammatory mediators production, intraligamentary injection technique of dexamethasone $(0.4 \mathrm{ml} / 8 \mathrm{mg} / 2 \mathrm{ml})$ and piroxicam $(0.4 \mathrm{ml} / 20 \mathrm{mg} / \mathrm{ml})$ was used in this study as it enables the application of the antiinflammatory agents in the periapical intraosseous region directly without undergoing hepatic by-pass before reaching the target site, so the bioavailability of the injected drug will be $100 \%{ }^{(7,17)}$.

The intraligamentary injection was administered using specialized pressure syringe. Pressure syringes offer many advantages over the conventional syringe as they deliver a specified dose of local anaesthetic solution and anti-inflammatory solution. They also allow the administrator to overcome the significant tissue resistance encountered ${ }^{(22)}$.

This study was conducted as a double-blind parallel randomized clinical trial in which randomization permits the same chance for each patient allocation to either the intervention or the comparator group without operator's interference. The outcomes of the groups were compared after sufficient follow-up time. This should provide an unbiased estimate of the treatment effect ${ }^{(23)}$.

The pain was recorded using the Numerical Rating Scale (NRS). NRS showed higher compliance rates, higher responsiveness, easier to use, better understood by most patients and good applicability relative to other pain scales ${ }^{(24,25)}$.

In the current study post-operative pain assessment was done at 4, 6, 12, 24 and 48-hours intervals as done by Atbaei and Mortazavi (2012) (11) and Mehrvarzfar et al. (2016) ${ }^{(21)}$. This was in harmony with Ali et al., (2012) (26) who reported that postoperative pain has a high occurrence rate during the first 24 hours after obturation and then decreases by time. 
Regarding the demographic data, in the present study, there was no statistically significant difference between the three groups regarding age, gender and the pre-operative pain. These factors were considered to be homogenous in all groups. This was in accordance to Raza et al. (2016) ${ }^{(27)}$ and Zeidan (2016) ${ }^{(28)}$, who showed that there was no effect of the patient's age and gender on endodontic postoperative pain.

Regarding the overall reduction in postoperative pain in the current study, there was a significant gradual reduction in postoperative pain in both intervention groups (dexamethasone and piroxicam) from 4 to 48 hours. These results were similar to those of Atbaei and Mortazavi (2012) (11) who reported a significant postoperative pain reduction after prophylactic intraligamentary injection with piroxicam during the same time interval and to those of Mehrvarzfar et al. (2016) ${ }^{(21)}$ who also reported a significant pain reduction after intraligamentary injection with dexamethasone up to 48 hours postoperatively.

Results of this study showed that there was no statistically significant difference in reduction of postoperative pain intensity in both group A (dexamethasone) and group B (piroxicam). This might be due to the injection of anti-inflammatory agents locally adjacent to the inflamed tooth to decrease the production of inflammatory mediators ${ }^{(7)}$.

These results also showed that there was a statistically significant reduction in postoperative pain intensity in group B (piroxicam) compared to group $\mathrm{C}$ (mepivacaine) at all time intervals. This was in agreement with Atbaei and Mortazavi (2012) $^{(11)}$ and Joshi et al. (2016) ${ }^{(20)}$ who reported that intraligamentary injection of piroxicam is effective in reducing post-operative pain which was attributed to the elimination half-life of piroxicam (50-hrs) due to a low systemic clearance rate, so it can overcome intense pain up to 48 -hours ${ }^{(17)}$. However, by comparing group A (dexamethasone) and group $\mathrm{C}$ (mepivacaine), there was only a statistically significant reduction in postoperative pain intensity at 4, 24 and 48 hour time intervals. This was in agreement with Mehrvarzfar et al. (2008) (7) and Pochapski et al. (2009) (19) who reported a significant reduction in postoperative pain intensity after preoperative administration of dexamethasone at those time intervals. On the other hand, there was no statistically significant difference between the two groups at 6 and 12 hours. This was in disagreement with Mehrvarzfar et al. (2008) (7) and Mehrvarzfar et al. (2016) ${ }^{(21)}$. Variation in results may be attributed to the difference in the study methodology (irrigation technique, irrigation type, type of files used, and instrumentation technique), besides operator skills and sample size variations. It might also be due to the delayed onset of action of the glucocorticoids that might start several hours or days after administration as mentioned in a study by Nobuhara et al. (1993) ${ }^{(29)}$, where systemic administration of dexamethasone significantly decreased the number of PMN's in the periapical tissue after endodontic over-instrumentation but not until 48 hours postoperatively ${ }^{(18)}$.

The results of this study also revealed a prolonged significant postoperative pain reduction up to 48 hours in both dexamethasone and piroxicam groups compared to mepivacaine. This might be due to increased half-life of piroxicam (up to 50 hours) and the delayed onset of action of the systemically administered dexamethasone ${ }^{(17,18)}$.

\section{CONCLUSION}

Within the limitations of this study, it could be concluded that prophylactic intra ligamentary injection of dexamethasone and piroxicam showed a significant success in reducing endodontic postoperative pain compared to mepivacaine, while there was no clinical or statistical difference regarding using either dexamethasone or piroxicam. 


\section{REFERENCES}

1. Walton, R. \& Fouad, A. (1992). Endodontic interappointment flare-ups: a prospective study of incidence and related factors. J. Endod., 18(4), 172-177.

2. Keiser, K. \& Hargreaves, K. M. (2002). Building effective strategies for the management of endodontic pain. Endod. Top., 3(1), 93-105.

3. Polycarpou, N., Ng, Y.-L., Canavan, D., Moles, D. R. \& Gulabivala, K. (2005). Prevalence of persistent pain after endodontic treatment and factors affecting its occurrence in cases with complete radiographic healing. Int. Endod. J., 38(3), 169-178.

4. Nixdorf, D. R., Moana-Filho, E. J., Law, A. S., McGuire, L. A., Hodges, J. S. \& John, M. T. (2010). Frequency of persistent tooth pain after root canal therapy: a systematic review and meta-analysis. J. Endod., 36(2), 224-230.

5. Marshall, J.G. \& Walton, R.E. (1984). The effect of intramuscular injection of steroid on posttreatment endodontic pain. J. Endod., 10(12), 584-588.

6. Liesinger, A., Marshall, F. J. \& Marshall, J. G. (1993). Effect of variable doses of dexamethasone on posttreatment endodontic pain. J. Endod., 19(1), 35-39.

7. Mehrvarzfar, P., Shababi, B., Sayyad, R., Fallahdoost, A.\& Kheradpir, K. (2008). Effect of supraperiosteal injection of dexamethasone on postoperative pain. Aust. Endod. J., 34(1), 25-29.

8. Shahi, S., Mokhtari, H., Rahimi, S., Yavari, H. R., Narimani, S., Abdolrahimi, M. \& Nezafati, S. (2013). Effect of premedication with ibuprofen and dexamethasone on success rate of inferior alveolar nerve block for teeth with asymptomatic irreversible pulpitis: a randomized clinical trial. J. Endod., 39(2), 160-162.

9. Khan, A. A. \& Dionne, R. A. (2002). COX-2 inhibitors for endodontic pain. Endod. Top., 3(1), 31-40.

10. Lalabonova, H., Kirova, D. \& Dobreva, D. (2005). Intraligamentary anaesthesia in general dental practice. J. IMAB, 11, 22-24.

11. Atbaei, A. \& Mortazavi, N. (2012). Prophylactic intraligamentary injection of piroxicam (Feldene) for the management of post-endodontic pain in molar teeth with irreversible pulpitis. Aust. Endod. J., 38(1), 31-35.

12. Shantiaee, Y., Mahjour, F. \& Dianat, O. (2012). Efficacy comparison of periapical infiltration injection of dexamethasone, morphine and placebo for postoperative endodontic pain. Int. Dent. J., 62(2), 74-78.
13. Elsharrawy, E. A. \& Elbaghdady, Y. M. (2007). A doubleblind comparison of a supplemental interligamentary injection of fentanyl and mepivacaine with 1: 200,000 epinephrine for irreversible pulpitis. J Pain Symptom Manag, 33(2), 203-207.

14. Alamassi, B. Y. (2017). Endodontic postoperative pain: Etiology and related factors - An Update. Int. J. Dent. Sci. Res., 5(2), 13-21.

15. Sathorn, C., Parashos, P. \& Messer, H. (2008). The prevalence of postoperative pain and flare-up in single-and multiple-visit endodontic treatment: a systematic review. Int. Endod. J., 41(2), 91-99.

16. Rogers, M. J., Johnson, B. R., Remeikis, N. A. \& BeGole, E. A. (1999). Comparison of effect of intracanal use of ketorolac tromethamine and dexamethasone with oral ibuprofen on post treatment endodontic pain. J. Endod., 25(5), 381-384.

17. Brunton LL, Lazo JS \& Parker KL. (2006). Goodman \& Gilman's The Pharmacological Basis of Therapeutics. 11th ed., P 671-715. NY: McGraw Hill.

18. Marshall, J G. (2002). Consideration of steroids for endodontic pain. Endod. Top., 3(1), 41-51.

19. Pochapski, M. T., Santos, F. A., De Andrade, E. D. \& Sydney, G. B. (2009). Effect of pretreatment dexamethasone on postendodontic pain. Oral Surg. Oral Med. Oral Pathol. Oral Radiol. Endod., 108(5), 790-795.

20. Joshi, N., Mathew, S., George, J. V, Hegde, S., Bhandi, S. $\&$ Madhu, K. S. (2016). Comparative evaluation of the efficacy of two modes of delivery of Piroxicam (Dolonex(®)) for the management of postendodontic pain: A randomized control trial. JCD, 19(4), 301-305.

21. Mehrvarzfar, P., Esnashari, E., Salmanzadeh, R., Fazlyab, M. \& Fazlyab, M. (2016). Effect of dexamethasone intraligamentary injection on post-endodontic pain in patients with symptomatic irreversible pulpitis: A randomized controlled clinical trial. Iran. Endod. J., 11(4), 261-266.

22. Malamed, S. F. (2019). HandBook of Local Anasthesia. 7th.ed., P 86-98, Elsevier, St. Louis.

23. Suresh, K. (2011). An overview of randomization techniques: An unbiased assessment of outcome in clinical research. J. Hum. Reprod. Sci., 4(1), 8-11.

24. Hjermstad, M. J., Fayers, P. M., Haugen, D. F., Caraceni, A., Hanks, G. W., Loge, J. H., Fainsinger, R., Aass, N., Kaasa, S. \& E. P. C. R. C. (2011). Studies comparing numerical rating scales, verbal rating scales, and visual analogue scales for assessment of pain intensity in adults: a 
systematic literature review. J. Pain Symptom Manag., 41(6), 1073-1093.

25. Breivik, H., Borchgrevink, P. C., Allen, S. M. \& Rosseland, L. A. (2008). Assessment of pain. BJ Anaesth, 101, 17-24.

26. Ali, S. G., Mulay, S., Palekar, A., Sejpal, D., Joshi, A.\& Gufran, H. (2012). Prevalence of and factors affecting post-obturation pain following single visit root canal treatment in Indian population: A prospective, randomized clinical trial. Contemp. Clin. Dent., 3(4), 459-463.

27. Raza, I., Ahmed, A., Khalid, N. \& Batool, F. (2016). Effect of occlusal reduction on frequency of post operative pain relief, following an endodontic instrumentation. Pakistan Oral Dent. J., 36(4), p. 650.

28. Zeidan, B. M. (2016). Evaluation the effect of occlusal reduction on postoperative pain in teeth with irreversible pulpitis and mild tenderness to percussion. Al-Rafidain Univ. Coll. Sci., 38, 128-140.

29. Nobuhara, W. K., Carnes, D. L. \& Gilles, J. A. (1993). Anti-inflammatory effects of dexamethasone on periapical tissues following endodontic overinstrumentation. J. Endod., 19(10), 501-507. 